\title{
Neonatal mortality and associated factors in the specialized neonatal care unit Asmara, Eritrea
}

Amanuel Kidane Andegiorgish ${ }^{1,2}$, Mihreteab Andemariam², Sabela Temesghen², Liya Ogbai², Zemichael Ogbe ${ }^{3}$ and Lingxia Zeng ${ }^{1,4^{*}}$ (i)

\begin{abstract}
Background: Limited knowledge on the magnitude of neonatal mortality and associated factors is hampering early intervention in African countries.

Objective: To determine neonatal mortality and associated factors in the Specialized Neonatal Care Unit Asmara, Eritrea.

Methods: Medical records of all neonates admitted to the Specialized Neonatal Care Unit in 2016 were reviewed using a cross-sectional study. The most important causes of admission and mortality were analyzed. Univariate and multivariate logistic regression analysis was used to evaluate the strength of risk factors associated with neonatal mortality. Variables significant at $P<0.20$ level in the univariate analysis were retained in the multivariate model. Model fit was evaluated using Hosmer and Lemeshow test (Chi-square $=12.89, \mathrm{df}=8 ; P=0.116$ ), implies the model's estimates fit the data at an acceptable level. Collinearity was assessed using variance inflation factor (VIF) $<4$. $P$-value $<0.05$ was considered statistically significant.

Results: Of the 1204 (59.9\% boys and 40.1\% girls) neonates admitted in 2016, 79 (65.6/1000 live births) died. The major causes of admission were sepsis (35.5\%), respiratory distress syndrome (15.4\%) and perinatal asphyxia (10\%). Major causes of death were respiratory distress syndrome (48.1\%); extremely low birth weight (40.9\%) and very low birth weight (30.5\%). After adjustment, low birth weight (Adjusted odds ratio ( $A O R)=4.55,95 \% \mathrm{Cl}, 1.97-10.50$ ), very low birth weight ( $A O R=19.24,95 \% \mathrm{Cl}, 5.80-63.78$ ), late admission (24 h after diagnosis) ( $\mathrm{AOR}=2.96,95 \% \mathrm{Cl}, 1.34-6.52$ ), apgar score (in 1 min $\mathrm{AOR}=2.28,95 \% \mathrm{Cl}, 1.09-4.76$, in $5 \mathrm{~min} \mathrm{AOR}=2.07,95 \% \mathrm{Cl}, 1.02-4.22$ ), and congenital abnormalities $(A O R=3.95,95 \% \mathrm{Cl}, 1.59-9.85)$ were significantly associated with neonatal mortality. Neonates that stayed $>24 \mathrm{~h}$ in the Specialized Neonatal Care Unit (AOR $=0.23,95 \% \mathrm{Cl}, 0.11-0.46$ ) had a lower likelihood of death. Overall $95.8 \%$ of mothers of neonates attended antenatal care and $96.6 \%$ were facility delivered. None of the maternal conditions were associated with neonatal mortality in this study.
\end{abstract}

Conclusions: Low birth weight, late admission, low apgar scores and congenital abnormalities were significantly associated with neonatal mortality in the Specialized Neonatal Care Unit. Early management of low birth weight, preterm births, and neonatal complications should be the priority issues for controlling local neonatal deaths.

Keywords: Neonatal mortality, Low birth weight, Associated factors, Specialized care unit, Eritrea

\footnotetext{
*Correspondence: tjzlx@mail.xjtu.edu.cn

'Department of Epidemiology and Biostatistics, School of Public Health, Xi'an

Jiaotong University Health Science Center, No 76 West Yanta Road, Xi'an

710061, Shaanxi Province, People's Republic of China

${ }^{4}$ Key Laboratory of Environment and Genes Related to Diseases, Xi'an

Jiaotong University, Ministry of Education, No 76 West Yanta Road, Xi'an

710061, Shaanxi Province, People's Republic of China

Full list of author information is available at the end of the article
}

(c) The Author(s). 2020 Open Access This article is distributed under the terms of the Creative Commons Attribution 4.0 International License (http://creativecommons.org/licenses/by/4.0/) which permits unrestricted use, distribution, and reproduction in any medium, provided you give appropriate credit to the original author(s) and the source, provide a link to the Creative Commons license, and indicate if changes were made. The Creative Commons Public Domain Dedication waiver (http://creativecommons.org/publicdomain/zero/1.0/) applies to the data made available in this article, unless otherwise stated. 


\section{Background}

Neonatal mortality, defined as death within the first 28 days of life, is a core indicator for neonatal health and wellbeing and is becoming a prominent component of overall under-five mortality. It is therefore receiving particular attention from Health authorities [1]. Even though the under- 5 mortality rate dropped by $47 \%$ (from 9.9 million to 5.6 million children) from 2000 to 2016 globally, the neonatal mortality rate only fell by $39 \%$ over the same period [2]. Of the 5.9 million under five deaths reported in 2015, 2.7 million died during the neonatal period [3]. In 2013, sub-Saharan Africa contributed nearly half of the worlds under- 5 mortality, mainly due to infectious diseases [4]. In 2017, UNICEF reported that neonatal mortality from sub-Saharan Africa and South Asia, accounted for 27/1000 live births. A child born from this region was nine times more likely to die in the first month of life than a child from a high-income country (https://data.unicef. org/topic/child-survival/neonatal-mortality/).

A number of previous studies have attempted to identify factors associated with neonatal admission $[5,6]$ and mortality [7-11]. Sepsis $[6,12]$, respiratory distress syndrome $[9,11-13]$, preterm birth $[9,12,14-16]$, low birth weight $[9,12,15-18]$, low apgars scores(a quantitative measure of neonatal vitality), at 1 and 5 min of birth [11, 12], low socioeconomic status $[9,10,14,19]$, cesarean section delivery [20], and neonatal age on admission [11, 14], are among the factors associated attributable factors of neonatal mortality $[9-15,19,20]$.

Eritrea, with a population of 4.95 million has made tremendous advances in reducing neonatal mortality from $232 / 1000$ in 1970 to $78.2 / 1000$ in 2010 and $17.8 / 1000$ in 2015 [21, 22]. The average annual reduction in underfive mortality rates from 1990 to 2013 in Eritrea was estimated to be $4.8 \%$ [23], whilst there was only $2.8 \%$ reduction for Africa and 2.9\% for sub-Saharan Africa over the same period [23, 24]. The Eritrean Health Bulletin (special edition 2016) revealed that, the neonatal mortality rate declined by $47 \%$ between 1990 and 2015 (from $34 / 1000$ in 1990 to $18 / 1000$ in 2015) [23]. The control of infectious diseases, especially malaria, have been involved in this decline, since $70 \%$ of the population lives in malarious areas. However, the decline has not continued since 2015 and no change in neonatal mortality over the last 4 years has been reported in Eritrea [22].

Neonatal health, evaluated by the overall survival of neonates per live births, is a basic means of evaluating the overall health of a nation $[19,25]$. Despite the fact that neonatal mortality rate in the specialized neonatal care unit (SNCU) in Asmara, Eritrea was lower than similar other neighboring countries $[6,11,14,26]$, neonates have still been dying, mainly from preventable causes. Implementations of effective neonatal care interventions are imperative for survival of neonates in developing countries $[13,15]$. The framework of sustainable development goals by the year 2030 is to end preventable deaths and reduce neonatal mortality to less than 12 per 1000 live births [2]. Health system research on the evaluation of interventions and outcomes should be strengthened to complement this goal $[10,25,27]$.

Therefore, this study was designed to evaluate neonatal mortality and associated factors among newborns admitted to the Specialized Neonatal Care Unit (SNCU) at Orotta National Referral Hospital (ONRH), Asmara, Eritrea in 2016.

\section{Methods}

\section{Study design}

A retrospective cross-sectional study was carried out to investigate neonatal mortality and associated factors among neonates admitted to the SNCU, Asmara, Eritrea.

\section{Study setting}

ONRH is the nation's tertiary hospital situated in Asmara, the capital city of Eritrea. The national referral hospital has different departments: Medical surgical, GynocologyObstetric (GynObs) and Pediatrics. Under the pediatric department there is a SNCU as detailed elsewhere [11].

The SNCU was established in 2003, through the collaboration of the Orotta teaching hospital, the Pediatric Association, and the Ministry of Health; with support from the Hummer Forum a German based Non-Governmental Organization. Later in 2013, other neonatal care units were established in four regional referral hospitals of the country.

The SNCU provides limited services on centralized oxygen supply, infusion pumps and incubators, radiant warmers and phototherapy equipment. It has no specialized nurses and ventilator machines, making it not qualified to provide care for preterm babies requiring the highest level of care.

\section{Study population}

Information of all the 1414 neonates admitted to the SNCU from January $1^{\text {st }}$-December $31^{\text {st }}, 2016$ was retrieved and 1204 (85.1\%) with complete information were included in the study. Neonates, either discharged immediately with advice, referred for further management or dead on arrival were excluded in accordance to the international classification of diseases (ICD-10).

\section{Data collection}

Data was collected from four sources, i.e. the neonatal admission (log book), patient's card, discharge form, and death registers. All information properly labeled by a neonatology specialist in register as per the ICD-10 standard was extracted using a structured checklist $[11,28]$. Information on primary admission diagnosis (Sepsis, RDS, 
Perinatal asphyxia), gestational age ( $>=\mid<37$ weeks) and size appropriate for gestational age (AGA), small for gestational age (SGA) and large for gestational age (LGA), mode of delivery (spontaneous vaginal delivery (SVD)/ cesarean section), place of delivery (gynecology-obstetric (GynObs), other facility/home), diagnosis to admission time $(</>=1 \mathrm{~h}$ ), birth weight (normal birth weight (NBW), high birth weight (HBW), low birth weight (LBW), and very low birth weight (VLBW)), congenital anomality (yes/ no), apgar scores (recorded either by the physician or primary care provider at the place of delivery), maternal age (years), obstetric complications (eclampsia/pre-eclampsia, diabetes mellitus), antenatal care visits, gravida and neonatal death (yes/no) was collected.

Small for gestational age (SGA), was defined as having a first weight recorded of less than the $10^{\text {th }}$ percentile and large for gestational age was defined as admission weight greater than $90^{\text {th }}$ percentile of weight-for-age and sex as defined by Intergrowth standards [28].

Data was collected by 3 public health graduates with previous experience. They were trained by the principal investigator and the neonatologist concerning the purpose of the study. The questionnaire was pretested on 20 neonatal cards of different admission years and modified according to the pre-test findings. Two hundred and ten $(14.9 \%)$ of the initial 1414 neonates with incomplete information were excluded resulting in information on 1204 neonate's admitted from $1^{\text {st }}$ of January to $31^{\text {st }}$ of December 2016.

\section{Statistical analysis}

Double data input was performed using CSPro (version7) software, and was exported to SPSS statistical package version 20 for windows (SPSS Inc., Chicago, IL, USA) for analysis. Quantitative indices are expressed as means \pm standard deviations using t-test. Categorical variables are presented using frequency and percentage. Univariate and multivariate logistic regression analysis was performed to evaluate the strength of the relationship between neonatal death and risk factors. Variables that were significant at $P$ value of $<0.20$ level in the univariate analysis were included and retained in the multivariate model. We evaluated model fit through inspection of Hosmer and Lemeshow test (Chi-square $=12.89, \mathrm{df}=8$; $P=0.116)$, which implies that the model's estimates fit the data at an acceptable level. The potential presence of collinearity was assessed using variance inflation factor (VIF) $<4$, and no collinearity was detected. Although $p>0.20$ for gender and maternal conditions in the univariate analysis, we retained in the multivariate analysis based on the existing literature [11]. Furthermore, in the multivariate analysis, adjustment was made on neonatal and maternal conditions. Odds ratios (OR) and 95\% confidence intervals $(95 \%$ CIs) were calculated for each factor. Two-tailed $P<0.05$ was considered statistically significant.

\section{Ethical considerations}

Ethical approval was sought out from the Ministry of Health research ethics and protocol review committee in Asmara, Eritrea. Medical directors of ONRH, Pediatric department and the SNCU were briefed on the objectives of the study and written consent was obtained.

\section{Results}

Ninety six percent of mothers of neonates had visited antenatal care during their pregnancy and $84.8 \%$ of the studied neonates were delivered in the tertiary GynObs unit of the hospital. Overall, 79.1\% were delivered through spontaneous vaginal delivery and $20.9 \%$ through cesarean sections.

Ninety four percent were healthy mothers, while 3\% had elevated blood pressure during pregnancy (eclampsia/preeclampsia). A total of 17 (1.7\%) mothers had traditional practices for their neonates, such as uvilectomy, circumcision and initiation of additional foods (like butter) (Table 1).

\section{Causes of admission in to SNCU}

As elsewhere, sepsis (culture proven or suspected) [11], was the major (35.5\%) cause of admission, followed by RDS (15.4\%), and perinatal asphyxia (10\%). Thirty three percent of admitted neonates were LBW. The minimum recorded birth weight was $800 \mathrm{~g}$. Congenital abnormality, including neural tube defect, digestive tract obstruction, anal-imperforation, congenital heart disease, and Downs syndrome, were among the commonly reported neonatal disorders 82 (6.8\%). In addition, 95 (7.9\%) neonates were admitted for observational follow-up (Table 2).

\section{Causes of neonatal mortality}

Seventy-nine neonates died in 2016 in the SNCU. Preterm births with its complications were the major causes of neonatal mortality. RDS accounted for the highest ( $n=38,48.1 \%$ ) cause of mortality followed by sepsis $(n=15,19 \%)$ and congenital malformation $(n=8,10.1 \%)$ (Fig. 1).

\section{Neonatal mortality and associated factors}

Overall neonatal mortality in the SNCU was 65.6/1000 live births. There was a significant association between low gestational age ( $<37$ weeks), LBW $(<2500 \mathrm{~g})$ and mortality $(P<0.001)$ (Table 3$)$. The majority $(40.9 \%)$ of extremely LBW (<1000 g) neonates died.

Apgar score was $>7$ for $61.2 \%$ and $79.8 \%$ in the first 1 and 5 min respectively. A significant inverse association was detected between Apgar score and neonatal mortality $(P<0.001)$ (Table 3$)$. 
Table 1 Demographic and Clinical Characteristics of neonates admitted to SNCU

\begin{tabular}{lll}
\hline Variables & Number & Percent (\%) \\
\hline Gender & & \\
Male & 721 & 59.9 \\
Female & 483 & 40.1
\end{tabular}

Gestation Age (Weeks)

Full-term $(>=37$ weeks $)$

Preterm $(<37$ weeks)

242

20.1

Birth Weight (Kg)

High birth weight $(>=4)$

Normal birth weight (2.5-3.99)

43

Low birth weight (1.5-2.49)

Very Low birth weight (1.0-1.49)

Extremely Low birth weight $(<1.0)$

Diagnosis to Admission time

$$
<1 \mathrm{~h}
$$

$1 \mathrm{~h}-24 \mathrm{~h}$

$>=24 \mathrm{~h}$

Apgar Score (1 min) ${ }^{a}$

Good Vitality $(>=7)$

Poor Vitality $(<7)$

Apgar Score $(5 \mathrm{~min})^{\mathrm{a}}$

Good Vitality

Poor Vitality

Length of stay in SNCU

$$
\begin{aligned}
& <=1 \text { day } \\
& >1 \text { day }
\end{aligned}
$$

Congenital Abnormality

Yes

No

Place of Delivery

Gynecology-Obstetrics

Other health facilities

Home Delivery

Mode of Delivery

Spontaneous vaginal delivery

Elective CS

Emergency CS

Gestational Size

Appropriate for Gestational Age

Small for Gestational Age

Lare for Gestational Age

Mother Age

$$
40+
$$

30-39
Table 1 Demographic and Clinical Characteristics of neonates admitted to SNCU (Continued)

\begin{tabular}{lll}
\hline Variables & Number & Percent (\%) \\
\hline $20-29$ & 679 & 56.4 \\
$<20$ & 49 & 4.1 \\
Maternal Condition & & \\
Normal & 1130 & 93.9 \\
Eclampsia/Pre-eclampsia & 37 & 3.1 \\
Diabetes Mellitus & 9 & 0.7 \\
Urinary Tract Infection & 8 & 0.6 \\
Others & & 1.7 \\
Antenatal Visit & 20 & \\
Yes & & 95.8 \\
No & 1154 & 4.2 \\
Traditional Practice & 50 & \\
Circumcision & & 0.5 \\
Uvilectomy & 6 & 0.7 \\
Additional Food & 9 & 0.2 \\
No traditional practice & 2 & 98.6 \\
\hline
\end{tabular}

${ }^{\mathrm{a}} \mathrm{N}$ doesn't include missing values

${ }^{\mathrm{b}}$ Anemia, Cardiac disease, Febrile, Candidacies, HIV, and Epilepsy

Table 2 Causes of admission in to SNCU

\begin{tabular}{lll}
\hline Causes of Admission & Frequency & Percent (\%) \\
\hline Sepsis & 428 & 35.5 \\
Respiratory distress syndrome & 185 & 15.4 \\
Perinatal asphyxia & 120 & 10.0 \\
For observation & 95 & 7.9 \\
Pneumonia & 87 & 7.2 \\
Congenital malformation & 52 & 4.3 \\
Jaundice & 44 & 3.7 \\
Hypernatrmic dehydration & 38 & 3.2 \\
Meconium aspiration syndrome & 28 & 2.3 \\
Hypothermia & 26 & 2.2 \\
Anemia & 19 & 1.6 \\
Gastrointestinal problem & 18 & 1.5 \\
Skin infection & 17 & 1.4 \\
Hypoglycemia & 16 & 1.3 \\
Trauma & 12 & 1.0 \\
Mastitis & 9 & 0.7 \\
Post circumcision / Uviloectomy bleeding & 5 & 0.4 \\
Renal problem & 5 & 0.4 \\
Total & 1204 & 100.0 \\
\hline 52 of the 82(63.4\%) congenita matormaton nonas were dagnosed
\end{tabular}

52 of the $82(63.4 \%)$ congenital malformation neonates were diagnosed on admission 


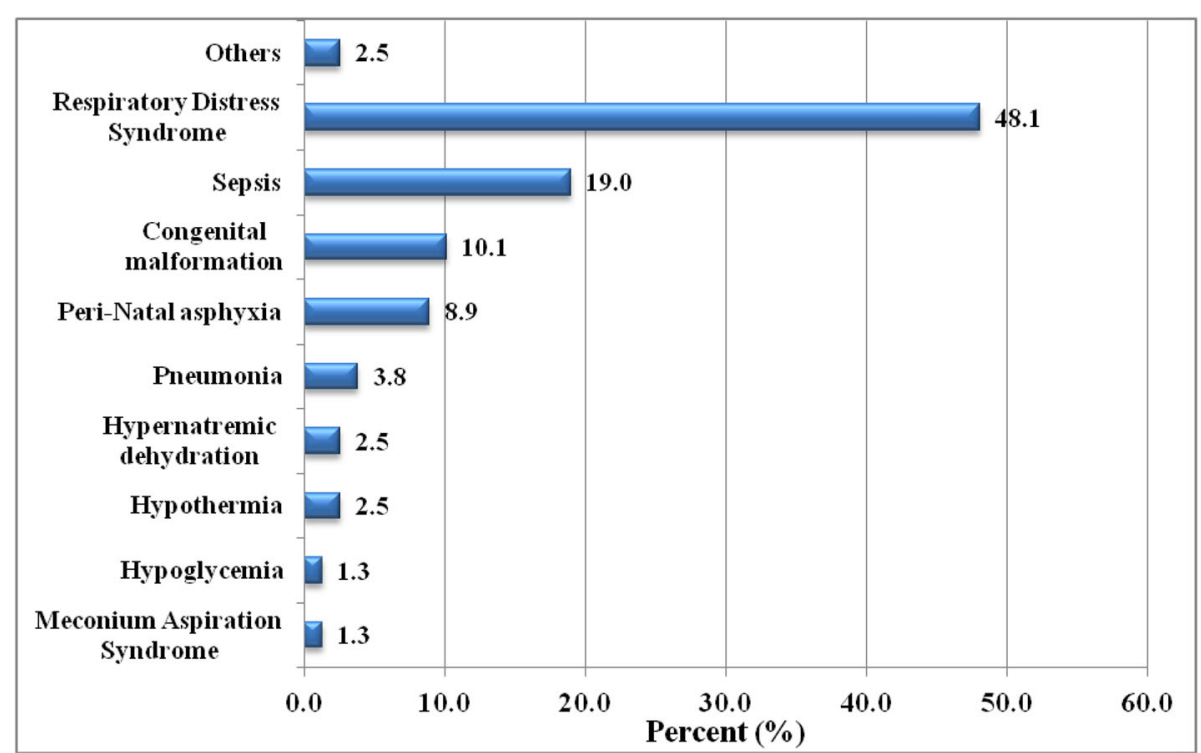

Fig. 1 Cause of mortality in the SNCU. (Others: carbon dioxide poisoning and severe anemia)

Neonates with a congenital abnormality were also more likely to die $(P<0.001)$ as were length of stay $(>1$ day) in the SNCU and place of delivery other than the tertiary GynObs $(P<0.05)$ (Table 3$)$. However, mode of delivery, SVD (79.1\%), elective cesarean section (10.7\%), or emergency cesarean section (10.2\%) and place of delivery (home vs health facility) were not associated with neonatal mortality $(P>0.05)$.

\section{Multivariate logistic regression analysis of neonatal and maternal variables association with neonatal mortality}

Neonatal mortality among VLBW neonates was 19.24 times higher than normal birth weights, (AOR, 19.24, 95\% CI: 5.80-63.78), and 4.55 times higher among LBW neonates (AOR, 4.55, 95\% CI: 1.97-10.50) compared to NBW. Congenital abnormality neonates were 3.95 times more likely to die (AOR, 3.95, 95\% CI: 1.59-9.85). Late admitted (after 24h) neonates were almost three times more likely to die compared to their counterparts (AOR, 2.96, 95\% CI:1.34-6.52). No association was found between maternal history of obstetric complications, multigravida and neonatal mortality. However, neonates of mothers who attended antenatal care were $72 \%$ less likely to die (Table 4).

\section{Discussion}

Overall, mortality among newborns admitted to the SNCU was 65.6/1000 live births. LBW and preterm births were the major associated factors of neonatal mortality, in which $66.6 \%$ of LBW and $50.6 \%$ of preterm neonates died. Previous studies concluded that these two factors were the direct and indirect causes of neonatal mortality $[7-9,14,25,26]$. Preterm births are at high risk of RDS due to pulmonary surfactant deficiency in the lungs and are prone to hospital admission and death [12, 13, 29, 30]. Several interlinked factors could have resulted for this up surge in LBW babies, such as in-utero growth restriction associated with poor nutritional status of mothers of secondary to low socio-economic status [9, 10, 16-18].

Even though neonatal mortality in the SNCU was lower than similar settings of similar countries the causes of deaths remain the same $[5,6,31]$. Apgar score, a quantitative measure of neonatal vitality was significantly lower among deceased neonates both in $1 \mathrm{~min}$ ( $4.95 \pm 1.88$ vs $6.55 \pm 1.73)$ and $5 \mathrm{~min}(6.26 \pm 1.92$ vs $7.80 \pm 1.52)$, consistent with studies from Ethiopia and Kenya [5, 31], but different to a study from Tanzania [12].

Logistic regression analysis indicated that congenitally abnormal neonates were 3 times more likely to die than their counterparts, inline to many studies $[12,25,29,32]$, in which majority of neonates with congenital abnormalities died [7]. Management of congenital abnormality neonates requires advanced facilities and skilled care; which is not available in Eritrea.

Similar to other studies, neonatal admissions [5, $11,30,33,34]$, and mortality were higher among boys than girls $(64.6 \%$ vs $35.4 \%)[25,34]$.

In common with other developing countries, sepsis, RDS and perinatal asphyxia accounted for more than $60 \%$ of admissions $[5,7,8,13,25,35]$. In addition, after preterm births many studies have underlined that infections are the main cause of neonatal admission and death after the first week of life $[8,12,14,21,36]$. Infections, LBW and alleviation of an unhygienic environment should be targeted to 
Table 3 Univariate analysis of baseline neonatal and maternal variables to predict neonatal mortality

\begin{tabular}{|c|c|c|c|c|}
\hline Variables & $\mathrm{N}$ & n (mortality/1000 live births) & OR \& 95\% Cl & $P$-value \\
\hline \multicolumn{5}{|l|}{ Gender } \\
\hline Female & 483 & $28(58)$ & 1 & \\
\hline Male & 721 & $51(71)$ & $1.24(0.77-1.99)$ & 0.381 \\
\hline \multicolumn{5}{|l|}{ Gestation Age (Weeks) } \\
\hline Full-tem(> = 37 weeks) & 962 & $39(41)$ & 1 & \\
\hline Preterm (<37 weeks) & 242 & $40(165)$ & $4.68(2.94-7.47)$ & $<0.001$ \\
\hline \multicolumn{5}{|l|}{ Birth Weight (KG) ${ }^{a}$} \\
\hline Normal birth weight & 766 & $24(31)$ & 1 & \\
\hline High birth weight & 43 & $2(47)$ & $1.51(0.35-6.60)$ & 0.379 \\
\hline Low birth weight & 305 & 25(82) & $2.76(1.55-4.91)$ & $<0.001$ \\
\hline Very low birth weight & 59 & 18(305) & 13.57(6.83-26.98) & $<0.001$ \\
\hline Extremely low birth weight & 22 & $9(409)$ & $21.40(8.34-54.91)$ & $<0.001$ \\
\hline \multicolumn{5}{|l|}{ Diagnosis to Admission time } \\
\hline$<1 \mathrm{~h}$ & 481 & $30(62)$ & 1 & \\
\hline $1 \mathrm{~h}-24 \mathrm{~h}$ & 306 & $14(46)$ & $0.72(0.38-1.38)$ & 0.324 \\
\hline$>=24 \mathrm{~h}$ & 417 & $35(84)$ & $1.38(0.83-2.29)$ & 0.215 \\
\hline \multicolumn{5}{|l|}{ Apgar Score $(1 \mathrm{~min})^{\mathrm{a}}$} \\
\hline Good Vitality $(>=7)$ & 616 & $17(28)$ & 1 & \\
\hline Poor Vitality $(<7)$ & 466 & 49(105) & $2.65(1.37-5.11)$ & 0.004 \\
\hline \multicolumn{5}{|l|}{ Apgar Score $(5 \mathrm{~min})^{\mathrm{a}}$} \\
\hline Good Vitality & 866 & $34(39)$ & 1 & \\
\hline Poor Vitality & 219 & $32(146)$ & $2.50(1.39-4.52)$ & 0.002 \\
\hline \multicolumn{5}{|l|}{ Length of Stay in SNCU } \\
\hline$<=1$ day & 203 & 20(99) & 1 & \\
\hline$>1$ day & 1001 & $59(59)$ & $1.75(1.03-2.97)$ & 0.040 \\
\hline \multicolumn{5}{|l|}{ Congenital Abnormality } \\
\hline No & 1122 & $66(59)$ & 1 & \\
\hline Yes & 82 & 13(159) & $3.01(1.59-5.73)$ & $<0.001$ \\
\hline \multicolumn{5}{|l|}{ Place of Delivery } \\
\hline Gynecology-Obstetrics & 1021 & $59(58)$ & 1 & \\
\hline Other Health Facility & 142 & 16(113) & $2.07(1.16-3.71)$ & 0.014 \\
\hline Home Delivery & 41 & $4(98)$ & $1.76(0.61-5.11)$ & 0.297 \\
\hline \multicolumn{5}{|l|}{ Mode of delivery } \\
\hline SVD & 952 & $70(74)$ & 1 & \\
\hline Elective CS & 129 & $4(31)$ & $0.40(0.15-1.12)$ & 0.082 \\
\hline Emergency CS & 123 & $5(41)$ & $0.53(0.21-1.35)$ & 0.185 \\
\hline \multicolumn{5}{|l|}{ Gestational Size } \\
\hline Appropriate for Gestational Age & 963 & $56(58)$ & 1 & \\
\hline Small for Gestational Age & 211 & $22(104)$ & $1.89(1.12-3.16)$ & 0.016 \\
\hline \multicolumn{5}{|l|}{ Maternal age } \\
\hline $20-29$ & 679 & $39(57)$ & 1 & \\
\hline$<20$ & 49 & $7(143)$ & $2.74(1.15-6.48)$ & 0.022 \\
\hline $30-39$ & 408 & $28(69)$ & $1.21(0.73-1.99)$ & 0.458 \\
\hline$>=40$ & 68 & $5(74)$ & $1.30(0.49-3.42)$ & 0.592 \\
\hline
\end{tabular}


Table 3 Univariate analysis of baseline neonatal and maternal variables to predict neonatal mortality (Continued)

\begin{tabular}{|c|c|c|c|c|}
\hline Variables & $\mathrm{N}$ & n (mortality/1000 live births) & OR \& 95\% Cl & P-value \\
\hline \multicolumn{5}{|c|}{ Obstetric complication } \\
\hline Normal & 1130 & $73(65)$ & 1 & \\
\hline Not normal & 74 & $6(81)$ & $1.28(0.54-3.04)$ & 0.580 \\
\hline \multicolumn{5}{|c|}{ Antenatal care Visits } \\
\hline yes & 1154 & $76(66)$ & 1 & \\
\hline No & 36 & $3(83)$ & $1.29(0.39-4.30)$ & 0.678 \\
\hline \multicolumn{5}{|l|}{ Gravidity } \\
\hline First & 436 & $29(67)$ & 1 & \\
\hline Multi & 768 & $50(65)$ & $0.98(0.61-1.57)$ & 0.924 \\
\hline
\end{tabular}

$n$ neonatal mortality in each group, CS-Cesarean Section

${ }^{\mathrm{a}} \mathrm{N}$ does not include missing cases

Table 4 Multivariate logistic regression output for neonatal and maternal variables

\begin{tabular}{|c|c|c|c|c|c|}
\hline Variables & B & S.E. & Wald & OR \& 95\% Cl & $p$-value \\
\hline Sex (Male vs Female) & 0.27 & 0.30 & 0.82 & 1.32(0.73-2.38) & 0.366 \\
\hline \multicolumn{6}{|l|}{ Birth weight } \\
\hline HBW vs NBW & 1.37 & 0.87 & 2.48 & $3.94(0.71-21.72)$ & 0.115 \\
\hline LBW vs NBW & 1.52 & 0.43 & 12.65 & $4.55(1.97-10.50)$ & $<0.001$ \\
\hline VLBW vs NBW & 2.96 & 0.61 & 23.38 & $19.24(5.80-63.78)$ & $<0.001$ \\
\hline Gestational age(<37wks vs > =37wks) & 0.38 & 0.41 & 0.84 & $1.46(0.65-3.26)$ & 0.360 \\
\hline \multicolumn{6}{|l|}{ Diagnosis to Admission time } \\
\hline $1-24 h$ vs $<1 \mathrm{~h}$ & 0.12 & 0.38 & 0.09 & $1.12(0.53-2.38)$ & 0.759 \\
\hline$>=24 \mathrm{~h}$ vs $<1 \mathrm{~h}$ & 1.08 & 0.4 & 7.20 & $2.96(1.34-6.52)$ & 0.007 \\
\hline Vitality $1 \min (<7$ vs > =7) & 0.82 & 0.38 & 4.83 & $2.28(1.09-4.76)$ & 0.028 \\
\hline Vitality $5 \min (<7$ vs > =7) & 0.73 & 0.36 & 4.01 & $2.07(1.02-4.22)$ & 0.045 \\
\hline Length of Stay in SNCU (> = 24 h vs $<24$ h) & -1.48 & 0.36 & 16.6 & $0.23(0.11-0.46)$ & $<0.001$ \\
\hline Congenital abnormality (yes vs no) & 1.37 & 0.47 & 8.70 & $3.95(1.59-9.85)$ & 0.003 \\
\hline \multicolumn{6}{|l|}{ Place of delivery } \\
\hline other facility vs GynObs & 0.70 & 0.48 & 2.15 & $2.01(0.79-5.11)$ & 0.143 \\
\hline home vs GynObs & -1.18 & 1.29 & 0.83 & $0.31(0.02-3.87)$ & 0.361 \\
\hline \multicolumn{6}{|l|}{ Mode of delivery } \\
\hline Elective CS vs SVD & -0.78 & 0.64 & 1.50 & $0.46(0.13-1.60)$ & 0.221 \\
\hline Emergency CS vs SVD & -0.01 & 0.56 & 0.00 & $0.99(0.33-2.95)$ & 0.981 \\
\hline Gestational size (SGA/AGA) & -0.41 & 0.37 & 1.27 & $0.66(0.32-1.36)$ & 0.260 \\
\hline \multicolumn{6}{|l|}{ Maternal age in years } \\
\hline$<20$ vs $20-29$ & 0.27 & 0.62 & 0.19 & $1.32(0.39-4.46)$ & 0.660 \\
\hline $30-39$ vs $20-29$ & -0.07 & 0.33 & 0.05 & $0.93(0.49-1.77)$ & 0.825 \\
\hline$>=40$ vs $20-29$ & -0.83 & 0.79 & 1.11 & $0.44(0.09-2.05)$ & 0.293 \\
\hline Obstetric Complications (Abnormal vs Normal) & 0.06 & 0.57 & 0.01 & $1.07(0.35-3.24)$ & 0.909 \\
\hline Antenatal care (no vs yes) & -1.29 & 0.96 & 1.78 & $0.28(0.04-1.83)$ & 0.182 \\
\hline Gravida (Multi vs First) & 0.17 & 0.33 & 0.26 & $1.18(0.62-2.27)$ & 0.612 \\
\hline
\end{tabular}


maximize neonatal recovery [5, 35]. It is worth mentioning that pneumonia and sepsis, major causes of admissions in 2006 , had declined by 66 and $50 \%$ respectively in this facility, and that the neonatal mortality rate had dropped by $18 \%$ despite the increased number of admissions compared to elsewhere [11]. This highlights that interventions on infection control, early diagnosis and treatment with improved hospital care are detrimental to neonatal survivals and must be further strengthened [12, 15, 25].

The majority $(84.8 \%)$ of babies were delivered in the tertiary GynObs hospital, inline with previous studies $[5,6,10,11,31]$. The mortality rate was twice as high among other facility born neonates, but the difference was not statistically significant. Late admission, after 24 $\mathrm{h}$ of illness was significantly associated with mortality, which is similar to other findings from low resources countries [10, 12, 13], but contrary to an Ethiopian study [6]. This highlights that the outcome of early, skilled interventions in Eritrea is crucial for a variety of risks to newborn deaths.

SVD accounted $79 \%$ births of the studied neonates, which is in line to previous studies [5, 11], but different from a Kenyan study [31], which showed that nearly half of admitted neonates were delivered through cesarean section. Mothers preference on cesarean section is not common in Eritrea.

Neonatal deaths stem from poor maternal health, inadequate nutritional status [16-18], or care during pregnancy $[9,10,14,35]$. Although no association was identified with maternal age, antenatal care visit, gravidity, and obstetric complications similar to other study [8], the high prevalence of neonatal mortality attributed to LBW may be a sign of poor maternal conditions $[9,10]$. The results from this single SNCU study highlights the need for early identification and appropriate management of risks to reducing neonatal mortality and make the sustainable development goals achievable [2, 12, 27].

\section{Limitations}

Using a cross-sectional study cause-effect relationship cannot be verified. Socioeconomic status (maternal education, household income and food security) for the most common associated risk factors of neonatal mortality in developing countries, especially in Africa, is not presented. Finally, our review was limited to documented cases and may under represent deaths of neonates born out of territory and during the first hospitalization, in which extreme low birth weight and congenital defects are at a higher risk of dying.

\section{Conclusion}

Low birth weight, late admission, low apgar scores and congenital abnormalities were significantly associated with neonatal mortality in the Specialized Neonatal Care Unit of Orotta National Referral Hospital (ONRH), Asmara, Eritrea in 2016. Early management of low birth weight, preterm births, and neonatal complications should be the priority issues for controlling local neonatal deaths. Knowing factors related to specific contexts and designing interventions for the associated burdens is important.

\section{Abbreviations \\ AOR: Adjusted Odd's Ratio; APA: Appropriate for Gestational Age; Cl: Confidence Interval; GynObs: Gynocology-Obstetric; LAG: Large for Gestational Age; LBW: Low Birth Weight; ONRH: Orotta National Referral Hospital; OR: Odd's Ratio; RDS: Respiratory Distress Syndrome; SGA: Small for Gestational Age; SNCU: Specialized Neonatal Care Unite}

\section{Acknowledgements}

We acknowledge the help we have received from the specialized neonatal care unit staffs. We thank Derek Charlwood for revising the English in the manuscript.

\section{Authors' contributions}

AKA conceived the study. MA, ST and LO collected data, entered, analyzed and wrote the initial draft of the study. AKA re-analyzed the data and wrote the report and edited finally by ZO and LXZ. All authors approved the final draft of the manuscript.

\section{Funding}

Not applicable.

\section{Availability of data and materials}

Pertinent data are presented in this manuscript. Additional data can be requested from the corresponding author upon reasonable request.

\section{Ethics approval and consent to participate}

Ethical approval was sought out from the Ministry of Health research ethics and protocol review committee in Asmara, Eritrea. Medical directors of ONRH, Pediatric department and the SNCU were briefed on the objectives of the study and written consent was obtained.

\section{Consent for publication}

Not applicable.

\section{Competing interests}

The authors declare that they have not competing interests.

\section{Author details}

'Department of Epidemiology and Biostatistics, School of Public Health, Xi'an Jiaotong University Health Science Center, No 76 West Yanta Road, Xi'an 710061, Shaanxi Province, People's Republic of China. ${ }^{2}$ Department of Epidemiology and Biostatistics, Asmara College of Health Sciences, School of Public Health, P.O.Box 8566, Asmara, Eritrea. ${ }^{3}$ Department of Neonatology, Orotta School of Medicine and Health Sciences, Orotta National Referral Hospital, Asmara, Eritrea. ${ }^{4}$ Key Laboratory of Environment and Genes Related to Diseases, Xi'an Jiaotong University, Ministry of Education, No 76 West Yanta Road, Xi'an 710061, Shaanxi Province, People's Republic of China.

Received: 12 June 2019 Accepted: 22 December 2019

Published online: 06 January 2020

\section{References}

1. You D, Hug L, Ejdemyr S, et al. Levels and trends in child mortality. Estimates developed by the UN Inter-agency Group for Child Mortality Estimation (IGME). Report 2015.

2. https://sustainabledevelopment.un.org/post2015/transformingourworld SDG-3, 3.2( accessed $9^{\text {th }}$ March 2019). Accessed Mar 2019.

3. Liu L, Oza S, Hogan D, et al. Global, regional, and national causes of under-5 mortality in 2000-15: an updated systematic analysis with implications for the sustainable development goals. Lancet. 2016;388(10063):3027-35. 
4. Liu L, Oza S, Hogan D, et al. Global, regional, and national causes of child mortality in 2000-13, with projections to inform post-2015 priorities: an updated systematic analysis. Lancet. 2015;385:430-40.

5. Gebremedhin D, Berhe H, Gebrekirstos K. Risk Factors for Neonatal Sepsis in Public Hospitals of Mekelle City, North Ethiopia, 2015: Unmatched Case Control Study. PLoS One. 2016;11(5):e0154798.

6. Demisse AG, Alemu F, Gizaw MA, et al. Patterns of admission and factors associated with neonatal mortality among neonates admitted to the neonatal intensive care unit of University of Gondar Hospital, Northwest Ethiopia. Pediatr Health Med Therapeut. 2017:8:57-64.

7. Sankar MJ, Natarajan CK, Das RR, et al. When do newborns die? A systematic review of timing of overall and cause-specific neonatal deaths in developing countries. J Perinatol. 2016;36(S1):S1-S11.

8. Thapa B, Thapa A, Aryal DR, et al. Neonatal sepsis as a major cause of morbidity in a tertiary center in Kathmandu. J Nepal Med Assoc. 2013; 52(192):549-56.

9. Lawn JE, Cousens S, Zupan J. 4 million neonatal deaths: when? Where? Why? Lancet. 2005;6736(05):71048-55.

10. Akinyemi JO, Bamgboye EA, Ayeni O. Trends in neonatal mortality in Nigeria and effects of bio- demographic and maternal characteristics. BMC Pediatr. 2015;15(36):1-12.

11. Shah $\mathrm{S}$, Zemichael $\mathrm{O}$, Meng $\mathrm{H}$. Factors associated with mortality and length of stay in hospitalized neonates in Eritrea, Africa. BMJ Open. 2012;2:e000792.

12. Ersdal HL, Mduma E, Svensen E, et al. Birth asphyxia: a major cause of early neonatal mortality in a Tanzanian rural hospital. Pediatrics. 2012;129:1238-43.

13. Kamath BD, MacGuire ER, McClure EM, et al. Neonatal mortality from respiratory distress syndrome: lessons for low-resource countries. Pediatrics. 2011;127(0):1-8.

14. Tewabe T, Mehariw $Y$, Negatie $E$, et al. Neonatal mortality in the case of Felege Hiwot referral hospital, Bhari Dar, Amhara Regional State, North West Ethiopia 2016: a one year retrospective chart review. Ital J Pediatr. 2018;44:57.

15. Gonzalez R, Merialdi M, Lincetto $\mathrm{O}$, et al. Reduction of neonatal mortality in China between 1990 and 2000. Pediatrics. 2006;117:499-954.

16. Haider BA, Olofin I, Wang M, et al. Anaemia, prenatal iron use, and risk of adverse pregnancy outcomes systematic review and metaanalysis. Br Med J. 2013:346:13443.

17. Lingxia Z, Leilei $P$, Chao L, et al. Iron deficiency Anaemia, current topics in Anemia, Jesmine Khan, Intech Open. https://doi.org/10.5772/intechopen.69048.

18. Lingxia Z, Cheng Y, Dang S, et al. Impact of micronutrient supplementation during pregnancy on birth weight, duration of gestation, and perinatal mortality in rural western China: double blind cluster randomised controlled trial. Br Med J. 2008;337:a2001.

19. Kayode GA, Grobbee DE, Amoakoh-Coleman M, et al. Variation in neonatal mortality and its relation to country characterstics in sub-Saharan Africa: an ecological study. BMJ Glob Health. 2017;2:e000209.

20. Bishop D, Dyer RA, Maswime S, et al. Maternal and neonatal outcome after caesarean delivery in the African surgical outcomes study: a 7-day prospective observational cohort study. Lancet Glob Health. 2019;7:e513-22.

21. Rajaratnam J, Marcus J, Flaxman A, et al. Neonatal, postneonatal, childhood, and under-5 mortality for 187 countries, 1970e2010: a systematic analysis of progress towards millennium development goal 4. Lancet. 2010;375:1988-2008,

22. UN Inter-agency Group for Child Mortality Estimation (UN IGME), September 2018. http://data.unicef.org

23. Ministry of Health (MOH) Eritrea.Department of Maternal and Child Health, Health Bulletin. Asmara: Ministry of Health, Department of Maternal and Child Health; 2016

24. Lawn J, Mongi P, Cousens S. Africa's newborns- counting them and making them count. Opportunity for Africa's Newborns: WHO; 2015. https://www.who. int/pmnch/media/publications/aonsection_l.pdf. (Accessed 30 Mar 2019).

25. Abdellatif M, Battashi AA, Ahmed M, et al. The patterns and causes of neonatal mortality at a tertiary Hospital in Oman. Oman Med J. 2013;28(6): 422-6.

26. Mohamed EY, Eldirdiri S, Gurashi HA, et al. Neonatal sepsis in a general SudaneseTeaching hospital, Sudan. Int J Pharm Med Res. 2015;3(1):177-9.

27. Bhutta ZA, Darmastadt GL, Hasan BS, et al. Community-based interventions for improving perinatal and neonatal health outcomes in developing countries: a review of the evidence. Pediatrics. 2005;115:519-617.

28. Villar J, Ismail LC, Victora CG, et al. International standard for newborn weight, length, and head circumference by gestational age and sex: the newborn cross-sectional study of the INTERGROWTH-2 $1^{\text {st }}$ project. Lancet. 2014;384:857-68.
29. Ashour BM, Gassier A, Shami Y, et al. Neonatal outcome in Misurata central hospital, Libya. J Sci. 2014:4(2):87-9.

30. Alebachew $G$, Teka B, Endris $M$, et al. Etiologic agents of bacterial Sepsis and their antibiotic susceptibility patterns among patients living with human immunodeficiency virus at Gondar University teaching hospital, Northwest Ethiopia. Biomed Res Int. 2016;2016:5371875.

31. Nkuranga JB. (Thesis), Pattern of admission, care and outcome of neonates managed in the neonatal intensive care unit at Kenyatta National Hospital: University of Nairobi, Kenya; 2013. http://erepository.uonbi.ac.ke:8080/xmlui/ handle/11295/8255

32. Zile I, Ebela I, Rozenfelde IR. Risk factors associated with neonatal deaths among very low birth weight infants in Latvia. Curr Pediatr Res. 2016;21(1):64-8.

33. Saleem M, labal R. Shahzad Bokhari, et al. pattern of neonatal admissions \& its outcome in a tertiary care hospital of southern Punjab (a 5 years study). P J M H S. 2014:8:916-21.

34. Sridhar PV, Thammanna PS, Sandeep M. Morbidity pattern and hospital outcome of neonates admitted in a tertiary care teaching hospital, Mandya. Int J Sci Stud. 2015;3(6):126-9.

35. Adatara P, Afaya A, Salia SM, et al. Risk Factors Associated with Neonatal Sepsis: A Case Study at a Specialist Hospital in Ghana. Scientific World J. 2019;2019:9369051.

36. Hayun M, Alasiry E, Daud D, et al. The risk factors of early onset neonatal Sepsis. Am J Clin Exp Med. 2015;3(3):78-82.

\section{Publisher's Note}

Springer Nature remains neutral with regard to jurisdictional claims in published maps and institutional affiliations.
Ready to submit your research? Choose BMC and benefit from:

- fast, convenient online submission

- thorough peer review by experienced researchers in your field

- rapid publication on acceptance

- support for research data, including large and complex data types

- gold Open Access which fosters wider collaboration and increased citations

- maximum visibility for your research: over $100 \mathrm{M}$ website views per year

At BMC, research is always in progress.

Learn more biomedcentral.com/submissions 